\title{
Associations between insulin and glucose concentrations and anthropometric measures of fat mass in Australian adolescents
}

\author{
Elizabeth Denney-Wilson ${ }^{1 *}$, Christopher T Cowell ${ }^{2}$, Anthony D Okely ${ }^{3}$, Louise L Hardy ${ }^{4}$, Robert Aitken ${ }^{4}$, \\ Timothy Dobbins ${ }^{5}$
}

\begin{abstract}
Background: One of the most serious, yet common co-morbidities of obesity is insulin resistance, which if untreated may progress to type 2 diabetes. This paper describes the insulin and glucose concentration distributions, the prevalence of elevated insulin, the associations between insulin and body mass index (BMI), waist circumference, waist-to-height ratio (WHtR) and fat mass index in a representative sample of Australian adolescents.

Methods: Cross-sectional population-based study of adolescent boys and girls ( $N=496$, mean age 15.3 years) attending schools in metropolitan Sydney, Australia. Fasting venous blood collected and analysed for insulin and glucose concentrations. Height, weight, waist circumference measured, BMI and waist-to-height ratio calculated. Pubertal status self-reported.
\end{abstract}

Results: Glucose concentrations were normally distributed and were not associated with adiposity. Insulin concentrations were distributed logarithmically, were higher among girls than boys overall and within the same ranges of BMI and waist circumference, but were lower among girls than boys within the same ranges of fat mass adjusted for height. The prevalence of elevated insulin concentration (defined as $>100 \mathrm{pmol} / \mathrm{L}$ ) was $15.9 \%$ and $17.1 \%$ among boys and girls, respectively. Correlations between insulin concentration and BMI, waist circumference, WHtR and fat mass adjusted for height were 0.53, 0.49, 0.51 and 0.55, among boys, respectively, and 0.35, 0.40, 0.42 and 0.34 , among girls, respectively.

Conclusions: Elevated insulin is highly correlated with adiposity in adolescents. BMI and WHtR are simple measures that can be used to identify young people who should be screened for insulin resistance and other co-morbidities.

\section{Background}

Overweight and obese children and adolescents are at increased risk for the development of a range of chronic, debilitating health problems [1]. Just as the prevalence of obesity among children and adolescents is increasing, so is the prevalence of type 2 diabetes, the metabolic syndrome, fatty liver disease and cardiovascular disease [2]. However, it is not clear which young people should be screened for co-morbidities, or which anthropometric

\footnotetext{
* Correspondence: e.denney-wilson@unsw.edu.au

'University of New South Wales Research Centre for Primary Health Care and Equity, Sydney, 2052, Australia

Full list of author information is available at the end of the article
}

measure provides the best guidance to clinicians as to the level of risk and the need for further investigation.

Very little is known about the population prevalence and distribution of adverse concentrations of insulin, the nature of the distributions of glucose and insulin concentrations and the nature of the associations between glucose and insulin concentrations and adiposity among young people. There have been three reports on glucose and insulin concentrations based on population samples. Allard et al. [3] described insulin and glucose concentration distributions among 9, 13 and 16 year old Quebec students $(\mathrm{n}=2,244)$, Wennlöf et al. [4] did the same for 9 and 15 year old Swedish students $(\mathrm{n}=1137)$ and

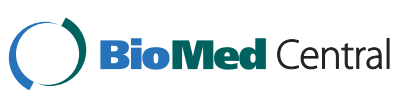

(c) 2010 Denney-Wilson et al; licensee BioMed Central Ltd. This is an Open Access article distributed under the terms of the Creative Commons Attribution License (http://creativecommons.org/licenses/by/2.0), which permits unrestricted use, distribution, and reproduction in any medium, provided the original work is properly cited. 
Thorsdottir et al. reported insulin concentration among 9 and 15 year old Icelandic students [5].

Several studies have assessed the associations between adiposity and glucose and insulin concentration. Steinberger et al. found that fasting insulin values were significantly higher among obese compared with non-obese adolescents [6]. Arslanian and Suprasongsin found that fasting insulin concentration was significantly correlated with percentage body fat (\%BF) among 20 peri-pubertal young people [7]. Misra et al., found that, among AsianIndian 14-18 year olds fasting insulin correlated significantly with BMI, \%BF, waist circumference and with skinfold thicknesses [8]. Wennlöf et al. reported that insulin concentration was only elevated in the highest decile of BMI among 15 year old Swedish boys and girls [4]. Garnett et al found that adolescents with a WHtR of greater than 0.5 were significantly more likely to have cardiovascular risk factors than those with a lower WHtR [9] while data from the Bogalusa Heart Study suggests that BMI and WHtR are both suitable anthropometric measures to identify children at risk of cardiovascular disease [10]. Finally, Thorsdottir et al. reported that the values of different measures of adiposity increased significantly across quartiles of insulin concentration [5]. These studies have various limitations, including: combining data for boys and girls; small sample sizes; combining young people in various stages of pubertal development; or using only a single measure of adiposity.

The purposes of this paper were to describe the population distributions of insulin and glucose concentration, the prevalence of elevated insulin concentrations and the associations between insulin concentration and BMI, waist circumference, waist-to- height ratio (WHtR) and fat mass index for boys and girls separately. The data were drawn from a representative sample of Grade 10 students (age range $14.3-17.1$ years) living in the Sydney (Australia) metropolitan area (population $=4.2$ Million).

\section{Methods}

The methods employed in the NSW Schools Physical Activity and Nutrition Survey, 2004 (SPANS 2004) have been described in detail elsewhere [11]. The study was approved by the University of Sydney Human Research Ethics Committee and the Government, Catholic and Independent school sectors and informed consent by the students and their carers was required for participation.

SPANS 2004 was a representative population survey of students attending kindergarten (Grade K) and Grades 2, 4, 6, 8 and 10 in primary and secondary schools in NSW, Australia. The data were collected from February to May 2004. Blood samples for the biomarker study reported here were only collected from Grade $10 \mathrm{stu}$ dents attending schools in the Sydney metropolitan area.
Standard methods were used to measure height, weight and waist circumference [11]. BMI was calculated $\left(\mathrm{kg} / \mathrm{m}^{2}\right)$ and categorised as not overweight/obese, overweight or obese using IOTF definitions [12]. Waistto-height ratio was calculated by dividing waist circumference (in $\mathrm{cm}$ ) by height (in $\mathrm{cm}$ ). Overnight fasting blood samples were analysed by an accredited laboratory. There is currently no consensus on a definition of "elevated" fasting insulin concentration among adolescents, however one of the authors (CTC), a pediatric endocrinologist, identified the value of fasting insulin at which clinicians would pursue further investigations and consider treatment as $>100 \mathrm{pmol} / \mathrm{L}$. Glucose concentrations greater than $110 \mathrm{mg} / \mathrm{dL}$ were defined as high based on the American Academy of Pediatrics' National Cholesterol Education Program definition [13].

Fat mass was estimated by calculating percentage body fat $(\% \mathrm{BF})$ using the regression equations of Taylor et al. [14] then calculating fat mass $(\mathrm{kg})$ as \%BF * body mass $(\mathrm{kg})$. Height correlated significantly with fat mass among boys $(\mathrm{r}=0.211, \mathrm{P}<0.001)$ and girls $(\mathrm{r}=0.215, \mathrm{P}=$ 0.002). The fat mass index (FMI) was therefore calculated as fat mass $(\mathrm{kg}) /$ height $(\mathrm{m})^{2}$. The FMI did not correlate significantly with height among boys $(\mathrm{r}=0.086$, $\mathrm{P}=0.142)$ or girls $(\mathrm{r}=0.070, \mathrm{P}=0.317)$.

Based on the pubertal ratings as determined by Tanner [15], boys were asked to self-report their stage of pubic hair development, while girls were asked to report their stage of breast development and age of menarche.

\section{Data analysis}

Data were analysed using SAS Version 9.1. Glucose and insulin concentration distributions were characterised and compared by sex and BMI category. Where data were log-normally distributed, values were log-transformed prior to analyses and reported as geometric rather than arithmetic means. Overall BMI, waist circumference, waist-to-height ratio and FMI quintiles were estimated and mean insulin concentrations calculated by quintile for boys and girls separately. Linear and logistic regression models adjusted for the survey design were used to test for differences in concentrations across BMI categories and between sexes.

\section{Results}

\section{Characteristics of the sample}

The characteristics of the sample are shown in Table 1. There was no significant difference in the prevalence of overweight and obesity combined among all Grade 10 students and those students who provided blood; $26.6 \%$ and $27.6 \%$, respectively, among boys and $18.9 \%$ and $19.4 \%$, among girls, respectively. Furthermore, the proportions in each BMI category were not significantly different between those who were invited to give blood and 
Table 1 Participation rates and characteristics of the sample

\begin{tabular}{|c|c|c|}
\hline & Boys & Girls \\
\hline n (\%) & $290(58.6)$ & $205(41.4)$ \\
\hline $\begin{array}{l}\text { Participation rate } \\
\text { (\%) }\end{array}$ & 40.7 & 39.4 \\
\hline \multicolumn{3}{|l|}{ Age (years) } \\
\hline mean $\pm \mathrm{SE}$ & $15.4 \pm 0.03$ & $15.4 \pm 0.03$ \\
\hline range & $14.3-17.1$ & $14.6-16.9$ \\
\hline Height (cm) & & $163.9 \pm 0.55$ \\
\hline mean $\pm S E$ & $173.5 \pm 0.32$ & 163.7 \\
\hline median & 173.7 & $148.0-178.9$ \\
\hline range & $153.0-192.0$ & \\
\hline \multicolumn{3}{|l|}{ Weight (kg) } \\
\hline mean $\pm S E$ & $66.3 \pm 1.14$ & $57.9 \pm 1.03$ \\
\hline median & 64.0 & 56.8 \\
\hline range & $38.7-139.4$ & $32.1-105.8$ \\
\hline \multicolumn{3}{|l|}{ BMI $\left(\mathrm{kg} / \mathrm{m}^{2}\right)$} \\
\hline mean $\pm S E$ & $21.9 \pm 0.34$ & $21.5 \pm 0.32$ \\
\hline median & 21.1 & 20.8 \\
\hline range & $15.3-41.4$ & $14.0-37.5$ \\
\hline \multicolumn{3}{|l|}{ BMI categories (\%) } \\
\hline $\begin{array}{l}\text { not overweight/ } \\
\text { obese }\end{array}$ & 72.4 & 80.5 \\
\hline overweight & 21.0 & 15.1 \\
\hline obese & 6.6 & 4.4 \\
\hline \multicolumn{3}{|l|}{$\begin{array}{l}\text { Waist circumference } \\
\text { (cm) }\end{array}$} \\
\hline mean \pm SE & $71.9 \pm 0.92$ & $65.8 \pm 0.91$ \\
\hline median & 69.8 & 64.7 \\
\hline range & $54.1-109.1$ & $48.9-101.8$ \\
\hline \multicolumn{3}{|l|}{$\begin{array}{l}\text { Waist to Height } \\
\text { Ratio }(\mathrm{cm} / \mathrm{cm})\end{array}$} \\
\hline mean $\pm S E$ & $0.41 \pm 0.005$ & $0.40 \pm 0.005$ \\
\hline median & 0.40 & 0.39 \\
\hline range & $0.33-0.64$ & $0.32-0.63$ \\
\hline \multicolumn{3}{|l|}{ Fat mass $(\mathbf{k g})$} \\
\hline mean \pm SE & $14.3 \pm 0.78$ & $17.8 \pm 0.80$ \\
\hline median & 11.6 & 15.9 \\
\hline range & $4.0-88.4$ & $4.8-66.8$ \\
\hline \multicolumn{3}{|l|}{ FMI $\left(\mathrm{kg} / \mathrm{m}^{2}\right)$} \\
\hline mean \pm SE & $4.7 \pm 0.25$ & $6.6 \pm 0.29$ \\
\hline median & 3.8 & 5.7 \\
\hline range & $1.5-26.2$ & $2.1-25.9$ \\
\hline
\end{tabular}

declined and those who agreed to give blood for boys $\left(\mathrm{X}_{2}{ }^{2}=0.51, \mathrm{P}=0.8\right)$ or girls $\left(\mathrm{X}_{2}^{2}=0.73, \mathrm{P}=0.7\right)$. More than $90 \%$ of boys and girls in this study were in the latter stages of puberty, and mean insulin values did not vary consistently across Tanner stages within BMI categories.
Table 2 Sample distributions of glucose $(\mathrm{mmol} / \mathrm{L})$ for boys and girls, combined and in not overweight/obese (NOO), overweight (Ow) and obese (Ob) BMI categories

\begin{tabular}{|c|c|c|c|c|c|c|c|c|c|}
\hline \multicolumn{5}{|c|}{ Boys } & \multicolumn{5}{|c|}{ Girls } \\
\hline & All & NOO & Ow & $\mathrm{Ob}$ & All & NOO & Ow & $\mathrm{Ob}$ & \\
\hline $\begin{array}{c}\mathbf{n} \\
\text { centile }\end{array}$ & 290 & 210 & 61 & 19 & 206 & 165 & 31 & 9 & $\begin{array}{c}\mathbf{n} \\
\text { centile }\end{array}$ \\
\hline 0 & 2.5 & 2.5 & 3.2 & 3.4 & 3.2 & 3.2 & 3.7 & 4.0 & 0 \\
\hline 5 & 3.9 & 4.0 & 3.7 & 3.4 & 4.0 & 4.0 & 3.9 & 4.0 & 5 \\
\hline 10 & 4.1 & 4.2 & 4.0 & 4.0 & 4.1 & 4.1 & 4.2 & 4.0 & 10 \\
\hline 15 & 4.2 & 4.2 & 4.3 & 4.2 & 4.2 & 4.2 & 4.2 & 4.1 & 15 \\
\hline 25 & 4.4 & 4.4 & 4.5 & 4.7 & 4.3 & 4.4 & 4.3 & 4.4 & 25 \\
\hline 30 & 4.5 & 4.4 & 4.6 & 4.7 & 4.4 & 4.4 & 4.3 & 4.4 & 30 \\
\hline 40 & 4.6 & 4.5 & 4.7 & 4.8 & 4.4 & 4.5 & 4.4 & 4.4 & 40 \\
\hline median & 4.7 & 4.6 & 4.7 & 4.8 & 4.5 & 4.5 & 4.6 & 4.4 & median \\
\hline 60 & 4.8 & 4.7 & 4.8 & 4.9 & 4.6 & 4.6 & 4.6 & 4.6 & 60 \\
\hline 70 & 4.9 & 4.8 & 4.9 & 5.0 & 4.7 & 4.7 & 4.8 & 4.9 & 70 \\
\hline 75 & 4.9 & 4.9 & 4.9 & 5.0 & 4.7 & 4.7 & 4.8 & 4.9 & 75 \\
\hline 85 & 5.1 & 5.1 & 5.1 & 5.2 & 4.8 & 4.8 & 4.8 & 4.9 & 85 \\
\hline 90 & 5.2 & 5.2 & 5.1 & 5.3 & 4.9 & 4.9 & 4.9 & 4.9 & 90 \\
\hline 95 & 5.3 & 5.3 & 5.2 & 5.7 & 5.1 & 5.1 & 4.9 & 4.9 & 95 \\
\hline 100 & 6.4 & 6.1 & 6.4 & 5.7 & 5.5 & 5.5 & 5.4 & 4.9 & 100 \\
\hline mean & 4.64 & 4.62 & 4.67 & 4.78 & 4.52 & 4.52 & 4.52 & 4.51 & mean \\
\hline SE & 0.03 & 0.03 & 0.08 & 0.09 & 0.03 & 0.03 & 0.07 & 0.11 & SE \\
\hline
\end{tabular}

Population distributions of glucose concentration

Glucose concentration was normally distributed among boys and girls and within each BMI category. Table 2 shows the mean $( \pm \mathrm{SE})$, the percentile values for the whole sample and for each BMI category, for boys and girls. For the whole sample, the values of glucose concentration ranged from $2.5-6.4 \mathrm{mmol} / \mathrm{L}$ and 3.2-5.5 $\mathrm{mmol} / \mathrm{L}$ among boys and girls, respectively. A value of $6.4 \mathrm{mmol} / \mathrm{L}$ in the boys' overweight category appeared to be atypically high. The distributions of glucose concentration were similar for boys and girls. Among boys, glucose concentration increased only slightly across BMI categories and among girls the distributions were similar across BMI categories. Among girls, atypically high values of $5.5 \mathrm{mmol} / \mathrm{L}$ in the healthy BMI category and $5.4 \mathrm{mmol} / \mathrm{L}$ in the overweight BMI category were noted.

\section{Population distributions of insulin concentration}

Table 3 shows the percentile values of insulin concentration for the whole sample and all BMI categories, for boys and girls. The values of insulin concentration ranged from 13.9-243.1 pmol/L and 13.9-284.7 pmol/L for boys and girls, respectively. The distributions were similar for boys and girls, although the values were slightly higher among girls across the distribution, up to approximately the $85^{\text {th }}$ percentile. Among boys, atypically high values of $222 \mathrm{pmol} / \mathrm{L}$ in the non-overweight/ obese BMI category and $215 \mathrm{pmol} / \mathrm{L}$ in the overweight 
Table 3 Sample distributions of insulin (pmol/L) for boys and girls, combined and in not overweight/obese (NOO), overweight $(\mathrm{Ow})$ and obese (Ob) BMI categories

\begin{tabular}{|c|c|c|c|c|c|c|c|c|c|}
\hline & & Boys & & & & & Girl & & \\
\hline & All & NOO & Ow & $\mathrm{Ob}$ & All & NOO & Ow & $\mathrm{Ob}^{*}$ & \\
\hline $\begin{array}{c}n \\
\text { centile }\end{array}$ & 290 & 210 & 61 & 19 & 206 & 165 & 31 & 9 & $\begin{array}{c}\mathrm{n} \\
\text { centile }\end{array}$ \\
\hline 0 & 13.9 & 13.9 & 34.7 & 48.6 & 13.9 & 13.9 & 34.7 & 41.7 & 0 \\
\hline 5 & 27.8 & 27.8 & 41.7 & 48.6 & 34.7 & 27.8 & 41.7 & 41.7 & 5 \\
\hline 10 & 27.8 & 27.8 & 48.6 & 48.6 & 34.7 & 34.7 & 48.6 & 41.7 & 10 \\
\hline 15 & 34.7 & 27.8 & 48.6 & 62.5 & 41.7 & 41.7 & 48.6 & 69.5 & 15 \\
\hline 25 & 41.7 & 34.7 & 55.6 & 104.2 & 48.6 & 48.6 & 55.6 & 69.5 & 25 \\
\hline 30 & 41.7 & 41.7 & 62.5 & 104.2 & 48.6 & 48.6 & 55.6 & 69.5 & 30 \\
\hline 40 & 48.6 & 41.7 & 69.5 & 132 & 55.6 & 55.6 & 62.5 & 97.2 & 40 \\
\hline median & 62.5 & 48.6 & 76.4 & 159.7 & 62.5 & 62.5 & 90.3 & 111.1 & median \\
\hline 60 & 69.5 & 62.5 & 90.3 & 180.6 & 76.4 & 69.5 & 118.1 & 159.7 & 60 \\
\hline 70 & 79.9 & 69.5 & 111.1 & 187.5 & 90.3 & 83.3 & 125 & 159.7 & 70 \\
\hline 75 & 90.3 & 76.4 & 118.1 & 187.5 & 97.2 & 90.3 & 132 & 159.7 & 75 \\
\hline 85 & 118.1 & 90.3 & 138.9 & 229.2 & 118.1 & 104.2 & 166.7 & 166.7 & 85 \\
\hline 90 & 138.9 & 104.2 & 152.8 & 229.2 & 132 & 118.1 & 173.6 & 166.7 & 90 \\
\hline 95 & 159.7 & 125 & 159.7 & 243.1 & 159.7 & 132 & 187.5 & 166.7 & 95 \\
\hline 100 & 243.1 & 222.2 & 215.3 & 243.1 & 284.7 & 284.7 & 194.5 & 166.7 & 100 \\
\hline Mean ${ }^{1}$ & 61.2 & 52.47 & 81.52 & 133.51 & 67.78 & 62.97 & 88.35 & 104.91 & Mean $^{1}$ \\
\hline $\mathrm{SE}^{2}$ & 0.05 & 0.05 & 0.05 & 0.09 & 0.05 & 0.05 & 0.12 & 0.2 & $\mathrm{SE}^{2}$ \\
\hline
\end{tabular}

1 Geometric mean

2 Standard error of the natural log of the geometric mean

BMI category were noted. Among girls, one atypically high value of $284 \mathrm{pmol} / \mathrm{L}$ in the non-overweight/obese BMI category were also noted. There was a statistically significant difference for males $(\mathrm{F}=50.84, \mathrm{p}<0.0001)$ and females $(\mathrm{F}=12.31, \mathrm{p}=0.005)$. Geometric mean insulin concentrations were statistically significantly higher in overweight $(t=6.59, \mathrm{p}<0.0001)$ and obese males $(\mathrm{t}=9.21, \mathrm{p}<0.0001)$ than in healthy males. A similar pattern was seen in overweight $(t=2.44$, $\mathrm{p}=0.0258)$ and obese $(\mathrm{t}=3.22, \mathrm{p}=0.0051)$ females.

\section{Prevalence of elevated insulin concentrations}

Overall, the prevalences of elevated insulin concentrations $>100 \mathrm{pmol} / \mathrm{L}$ were $19.3 \%$ and $22.4 \%$ among boys and girls, respectively. Among boys the prevalences of elevated insulin concentrations in the non-overweight, overweight and obese BMI categories were 7.1\%, 29.5\% and 68.4\%, respectively, and among girls, were $10.9 \%, 41.9 \%$ and $44.4 \%$, respectively. Statistically significant overall differences were found for males $\left(\mathrm{X}^{2}=59.4, \mathrm{p}<0.0001\right)$ and females $\left(X^{2}=21.9, p<0.0001\right)$. Specifically, overweight $\left(\mathrm{X}^{2}=12.7, \mathrm{p}=0.0004\right)$ and obese $\left(\mathrm{X}^{2}=36.9, \mathrm{p}<0.0001\right)$ males compared with healthy range males, and overweight $\left(\mathrm{X}^{2}=8.3, \mathrm{p}=0.0040\right)$ and obese $\left(\mathrm{X}^{2}=6.0, \mathrm{p}=0.0146\right)$ females compared with healthy range females.

\section{Associations between insulin and BMI, waist} circumference, WHtR and FMI

Inter-quintile ranges created for BMI, waist circumference, WHtR and FMI to enable insulin concentrations to be compared between boys and girls within the same ranges of BMI, waist circumference, WHtR and FMI. Table 4 shows the mean insulin concentrations for quintiles of BMI, waist circumference and FMI for boys and girls, separately. For BMI, among boys the concentrations did not vary across quintiles 1-3 but increased progressively and among girls the concentrations did not vary across quintiles 1 and 2 but increased progressively thereafter. The mean concentrations in the first four quintiles were higher among girls compared with boys, and similar in the $5^{\text {th }}$ quintile, although only the difference for the $3^{\text {rd }}$ quintile was statistically significant.

For waist circumference, the mean insulin concentrations were higher among girls at every quintile and became progressively higher for both boys and girls across quintiles 1-5. The differences between boys and girls were statistically significant for the $1^{\text {st }}, 3^{\text {rd }}$ and $4^{\text {th }}$ quintiles. The mean insulin concentration was higher in each quintile of WHtR in girls, but was statistically significant in the $3^{\text {rd }}$ quintile only. For FMI, insulin concentration increased consistently across quintiles 2-5 among boys and quintiles 3-5 among girls, but in contrast with BMI and waist circumference, insulin concentration among girls was equal to or lower than the values among boys in all quintiles except the second. The differences between boys and girls were statistically significant only the $5^{\text {th }}$ quintile.

Pearson correlation coefficients for the associations between insulin concentration and BMI, waist circumference, WHtR and FMI among boys were 0.53, 0.49, 0.51 and 0.55 , respectively, and the correlations among girls were $0.35,0.40,0.42$ and 0.34 , respectively. All were statistically significant at $\mathrm{P}<0.001$.

\section{Discussion}

This study surveyed a representative population sample of adolescents living in a developed economy. Glucose concentration was normally distributed and was not associated with BMI category or other measures of adiposity. In contrast, insulin concentration was logarithmically distributed and was positively associated with adiposity. Insulin concentration was higher among girls than boys overall and within the same ranges of BMI, waist circumference and WHtR but tended to be higher among boys than girls within the same ranges of FMI. Using BMI or waist circumference independently to study gender differences in insulin concentration or to establish cut-points is likely to lead to erroneous conclusions. WHtR $>0.5$ is a reliable option for identifying young people in need of further 
Table 4 Geometric mean values of insulin concentration (pmol/L) for percentile ranges of BMI $\left(\mathrm{kg} / \mathrm{m}^{2}\right)$, waist circumference $(\mathrm{cm})$ and fat mass index $\left(\mathrm{kg} / \mathrm{m}^{2}\right)$ for boys and girls

\begin{tabular}{|c|c|c|c|c|}
\hline \multirow[b]{2}{*}{ Centile ranges } & \multirow[b]{2}{*}{ BMI $\left(\mathrm{kg} / \mathrm{m}^{2}\right)$} & \multicolumn{3}{|c|}{ Mean Insulin conc. (pmol/L) } \\
\hline & & Boys & Girls & P-value of difference \\
\hline $0-20$ & $\leq 18.7$ & 49.5 & 58.9 & 0.16 \\
\hline $21-40$ & $18.8-20.3$ & 50.0 & 55.0 & 0.34 \\
\hline $41-60$ & $20.4-21.9$ & 49.4 & 70.0 & $<0.01$ \\
\hline $61-80$ & $22.0-24.3$ & 69.9 & 73.8 & 0.53 \\
\hline \multirow[t]{2}{*}{$81-100$} & $24.4-41.4$ & 95.6 & 92.0 & 0.74 \\
\hline & circumference & & & \\
\hline $0-20$ & $\leq 61.5$ & 43.6 & 56.3 & 0.02 \\
\hline $21-40$ & $61.6-65.7$ & 52.4 & 63.3 & 0.06 \\
\hline $41-60$ & $65.8-69.8$ & 53.9 & 71.3 & 0.01 \\
\hline $61-80$ & $69.9-75.6$ & 59.8 & 82.2 & 0.01 \\
\hline $81-100$ & 75.7-109.1 & 87.6 & 105.0 & 0.08 \\
\hline \multicolumn{5}{|c|}{ Waist to Height Ratio $(\mathrm{cm} / \mathrm{cm})$} \\
\hline $0-20$ & $\leq 0.37$ & 47.6 & 58.0 & 0.06 \\
\hline $21-40$ & $0.38-0.39$ & 55.2 & 59.9 & 0.37 \\
\hline $41-60$ & $0.40-0.41$ & 50.2 & 67.3 & 0.01 \\
\hline $61-80$ & $0.42-0.44$ & 66.9 & 74.9 & 0.41 \\
\hline \multirow[t]{2}{*}{$81-100$} & $0.45-0.64$ & 96.0 & 102.1 & 0.49 \\
\hline & FMI $\left(\mathrm{kg} / \mathrm{m}^{2}\right)$ & & & \\
\hline $0-20$ & $\leq 3.1$ & 50.9 & 52.3 & 0.85 \\
\hline $21-40$ & $3.2-4.2$ & 48.6 & 62.1 & 0.11 \\
\hline $41-60$ & $4.3-5.3$ & 65.4 & 55.3 & 0.13 \\
\hline $61-80$ & $5.4-7.1$ & 78.4 & 72.0 & 0.27 \\
\hline $81-100$ & 7.2-26.2 & 107.1 & 83.5 & 0.03 \\
\hline
\end{tabular}

screening, however different cut-points should be established for boys and girls, based on BMI.

Although the definition used in this paper to identify the prevalence of elevated insulin concentration is not based on international consensus, it is one that many pediatric endocrinologists may consider reasonable. It is notable that this cut-point lies between the $85^{\text {th }}$ and $90^{\text {th }}$ percentiles for boys in the non-overweight BMI category and between the $80^{\text {th }}$ and $85^{\text {th }}$ percentiles for girls in the nonoverweight BMI category. Its application showed that the prevalence of elevated insulin concentration was approximately $16-17 \%$ in this population sample. That the prevalence of elevated insulin concentrations were similar for overweight and obese girls was surprising, but may be explained by the fact that the sample only included nine obese girls, most of whose BMI values were close to the boundary between the overweight and obese categories.

Consistent with several other studies, we found that glucose concentrations were lower and insulin concentrations were higher among girls than boys [3-5,8]. Whereas the median (or mean) values of glucose concentration were similar across studies, the insulin concentration values differed markedly. Allard et al. [3] reported median glucose concentrations among 15 year olds of $5.3 \mathrm{mmol} / \mathrm{L}$ and $5.0 \mathrm{mmol} / \mathrm{L}$ and Misra et al. [8] means of $5.0 \mathrm{mmol} / \mathrm{L}$ and $4.9 \mathrm{mmol} / \mathrm{L}$ among boys and girls, respectively. The median values for the SPANS data reported here were $4.7 \mathrm{mmol} / \mathrm{L}$ and $4.5 \mathrm{mmol} / \mathrm{L}$ among boys and girls, respectively. With regard to insulin concentrations, Allard et al. [3] reported median insulin concentrations of $38.7 \mathrm{pmol} / \mathrm{L}$ and $46.4 \mathrm{pmol} / \mathrm{L}$, Misra et al. [8] reported means of $96.0 \mathrm{pmol} / \mathrm{L}$ and $118.8 \mathrm{pmol} / \mathrm{L}$, Wennlöf et al. [4] reported medians of $55.9 \mathrm{pmol} / \mathrm{L}$ and $48.0 \mathrm{pmol} / \mathrm{L}$ among boys and girls, respectively, and the SPANS study reported $54 \mathrm{pmol} / \mathrm{L}$ among both boys and girls. That is, the SPANS values were similar to those of Allard et al. and Wennlöf et al., but approximately half those of Misra et al.

Unfortunately, Allard et al. did not provide summary statistics for BMI for the Canadian sample and the mean BMI values of Misra et al.'s and Wennlöf et al.'s, samples were only slightly lower than those of the SPANS sample (data not shown). The small differences in adiposity between the samples would not appear to account for the very large differences between Misra et al.'s findings and the other studies, but it is plausible that ethnic differences 
between the samples may account for them [16]. Whereas Allard et al., Wennlöf et al. and SPANS sampled from primarily Europid populations, Misra et al. sampled from an Asian Indian population. Despite the differences between the SPANS and Misra et al.'s findings, the correlations between insulin concentration and BMI reported by Misra et al. ( $\mathrm{r}=0.62$ for boys and $\mathrm{r}=0.39$ for girls) were similar to those reported here.

The SPANS study had several limitations. First, participation rates were lower than would have been preferred, but we reported evidence that the sample was representative of the study population [17]. Second, the obese BMI category only included nine girls with a small range of BMI values, although the prevalence of obesity among girls in the biomarker sub-study was not statistically different from that in the study as a whole. The low number of girls may have influenced the finding that insulin concentrations at the $85^{\text {th }}$ and $95^{\text {th }}$ centiles among all boys and obese boys, were much higher than among girls. Similarly, the small number of obese girls may explain why the prevalence of elevated insulin concentration was relatively low among obese girls, compared with obese boys. Data from a greater number of obese girls with a greater range of BMI values would enhance the quality of the present findings, as would the collection of family history of diabetes.

\section{Conclusion}

This study provides a useful source of insulin reference values for clinicians collected on free-living adolescents and has characterized the nature of the relationship between insulin concentration and adiposity among adolescents. Although the definition of elevated insulin used in this study is somewhat arbitrary, the data suggest that elevated insulin concentrations are associated with excess adiposity in adolescents. Longitudinal studies are required to determine the long term sequela of elevated insulin from a relatively young age

\section{Acknowledgements}

The authors thank the participating schools, teachers and students. SPANS 2004 was funded by NSW Health.

\section{Author details \\ ${ }^{1}$ University of New South Wales Research Centre for Primary Health Care and Equity, Sydney, 2052, Australia. ${ }^{2}$ Institute of Endocrinology and Diabetes, Children's Hospital at Westmead, Westmead, 2145, Australia. ${ }^{3}$ Child Obesity Research Centre and Faculty of Education, University of Wollongong, Wollongong, 2522, Australia. ${ }^{4}$ Physical Activity, Nutrition and Obesity Research Group, University of Sydney, Sydney, 2006, Australia. ${ }^{5}$ Lowy Cancer} Research Centre, University of New South Wales, Sydney, 2052, Australia.

\section{Authors' contributions}

EDW was responsible for study design, data collection and interpretation and preparation of manuscript. CC provided advice to study coordinators, data interpretation and review of the manuscript. ADO was responsible for study management, study design, interpretation of results and review of the manuscript. LH oversaw data collection and provided review of the manuscript. RA and TD provided statistical analysis and reviewed the manuscript. All have read and agree with the final manuscript.

\section{Competing interests}

The authors declare that they have no competing interests.

Received: 3 February 2010 Accepted: 11 August 2010

Published: 11 August 2010

\section{References}

1. Lobstein $T$, Baur L, Uauy R: Obesity in children and young people: a crisis in public health. Obes Rev 2004, 1 (5 Suppl):4-104.

2. Cruz ML, Shaibi GQ, Weigensberg MJ, Spruijt-Metz D, Ball GD, Goran MI: Pediatric obesity and insulin resistance: chronic disease risk and implications for treatment and prevention beyond body weight modification. Annu Rev Nutr 2005, 25:435-68.

3. Allard P, Delvin EE, Paradis $G$, et al: Distribution of fasting plasma insulin, free fatty acids, and glucose concentrations and of homeostasis model assessment of insulin resistance in a representative sample of Quebec children and adolescents. Clin Chem 2003, 49:644-9.

4. Wennlöf AH, Yngve A, Nilsson TK, Sjostrom M: Serum lipids, glucose and insulin levels in healthy schoolchildren aged 9 and 15 years from Central Sweden: reference values in relation to biological, social and lifestyle factors. Scand J Clin Lab Invest 2005, 65:65-76.

5. Thorsdottir I, Gunnarsdottir I, Palsson Gl, Johannsson E: Anthropometric predictors of serum fasting insulin in 9- and 15-year-old children and adolescents. Nutr Metab Cardiovasc Dis 2006, 16:263-71.

6. Steinberger J, Moorehead C, Katch V, Rocchini AP: Relationship between insulin resistance and abnormal lipid profile in obese adolescents. J Pediatr 1995, 126:690-5.

7. Arslanian S, Suprasongsin C: Insulin sensitivity, lipids, and body composition in childhood: is "syndrome X" present? J Clin Endocrinol Metab 1996, 81:1058-62.

8. Misra A, Vikram NK, Arya S, Pandey RM, Wasir JS, Gupta VP: High prevalence of insulin resistance in postpubertal Asian Indian children is associated with adverse truncal body fat patterning, abdominal adiposity and excess body fat. Int J Obes Relat Metab Disord 2004, 28:1217-26.

9. Garnett SP, Baur LA, Cowell CT: Waist-to-height ratio: a simple option for determining excess central adiposity in young people. Int J Obes Relat Metab Disord 2008, 32:1028-30.

10. Freedman DS, Kahn HS, Mei Z, et al: Relation of body mass index and waist-to-height ratio to cardiovascular disease risk factors in children and adolescents: the Bogalusa Heart Study. Am J Clin Nutr 2007, 86:33-40.

11. Booth ML, Denney-Wilson E, Okely AD, Hardy LL: Methods of the NSW Schools Physical Activity and Nutrition Survey (SPANS). I Sci Med Sport 2005, 8:284-93.

12. Cole TJ, Bellizzi MC, Flegal KM, Dietz WH: Establishing a standard definition for child overweight and obesity worldwide: international survey. Br Med J 2000, 320(7244):1240-3.

13. NCEP Expert Panel on Blood Cholesterol Levels in Children and Adolescents, National Cholesterol Education Program (NCEP): Highlights of the Report of the Expert Panel on Blood Cholesterol Levels in Children and Adolescents. Pediatrics 1992, 89:495-501.

14. Taylor RW, Jones IE, Williams SM, Goulding A: Body fat percentages measured by dual-energy X-ray absorptiometry corresponding to recently recommended body mass index cutoffs for overweight and obesity in children and adolescents aged 3-18 y. Am J Clin Nutr 2002, 76:1416-21.

15. Tanner JM: Growth at adolescence: with a general consideration of the effects of hereditary and environmental factors upon growth and maturation from birth to maturity. Oxford: Blackwell Scientific, 21962

16. Zimmet P, Alberti KG, Shaw J: Global and societal implications of the diabetes epidemic. Nature 2001, 414(6865):782-7.

17. Booth ML, Okely AD, Denney-Wilson E, Hardy L, Yang B, Dobbins T: NSW Schools Physical, Activity and Nutrition Survey (SPANS) 2004: Full Report Sydney: NSW Department of Health 2006. 


\section{Pre-publication history}

The pre-publication history for this paper can be accessed here:

http://www.biomedcentral.com/1471-2431/10/58/prepub

doi:10.1186/1471-2431-10-58

Cite this article as: Denney-Wilson et al: Associations between insulin

and glucose concentrations and anthropometric measures of fat mass

in Australian adolescents. BMC Pediatrics 2010 10:58.

Submit your next manuscript to BioMed Central and take full advantage of:

- Convenient online submission

- Thorough peer review

- No space constraints or color figure charges

- Immediate publication on acceptance

- Inclusion in PubMed, CAS, Scopus and Google Scholar

- Research which is freely available for redistribution

Submit your manuscript at 